\title{
Framing Reflexivity in Quality Improvement Devices in the Care for Older People
}

\author{
Esther van Loon - Teun Zuiderent-Jerak
}

Published online: 1 July 2011

(C) The Author(s) 2011. This article is published with open access at Springerlink.com

\begin{abstract}
Health care organizations are constantly seeking ways to improve quality of care and one of the often-posed solutions to deliver 'good care' is reflexivity. Several authors stress that enhancing the organizations' and caregivers' reflexivity allows for more situated, and therefore better care. Within quality improvement initiatives, devices that guarantee quality are also seen as key to the delivery of good care. These devices do not solely aim at standardizing work practices, but are also of importance in facilitating reflexivity. In this article, we study how quality improvement devices position the relationship between situated reflection and standardization of work processes. By exploring the work of Michel Callon, Michael Lynch, and Lucy Suchman on reflexivity in work practices, we study the development and introduction of the Care Living Plan. This device aimed to transform care organizations of older people from their orientation towards the system of care into organizations that take a client-centred approach. Our analysis of the construction of specific forms of reflexivity in quality devices indicates that the question of reflexivity does not need to be opposed to standardization and needs to be addressed not only at the level of where reflexivity is organizationally situated and who gets to do the reflecting, but also on the content of reflexivity, such as what are the issues that care workers can and cannot reflect upon. In this paper we point out the theoretical importance of a more detailed empirical study of the framing of reflexivity in care practices.
\end{abstract}

Keywords Care for older people · Good care · Reflexivity · Quality improvement · Quality improvement devices

E. van Loon $(\bowtie) \cdot$ T. Zuiderent-Jerak

Institute of Health Policy and Management, Erasmus University Rotterdam,

P.O. Box 1738, 3000 DR Rotterdam, The Netherlands

e-mail: vanloon@bmg.eur.nl 


\section{Good Care, Reflexivity and the Importance of Devices}

Delivering quality of care that is 'good' is a contested matter, since there is no uniform label and way of doing 'good care'. Instead what is defined as good care is highly variable from one situation to the other. Anne-Mei The [17] showed through her anthropological research in Dutch nursing homes, how in daily care delivery, caregivers decide what good care is on the basis of various aspects such as: the individual client, the health status of the client, availability of staff and wider societal or policy debates. Annemarie Mol $[10,11]$ also emphasizes that what good care is, is ontologically multiple and dependant on the situation. As health and healthcare are done in different ways, the definition of good care strongly depends on how care institutions enact an illness, how individuals live with diseases and disabilities, and how 'quality' is defined. As notions of quality often clash when delivering care, such as when client preferences contradict with the professional opinion of the care worker, good care cannot be defined in a univocal way.

Care organizations and policymakers tend to recognize that due to the situated nature of quality, there is a need to allow for specific forms of variability in care delivery. Consequently, the notion of client-centred care is growing into one of the dominant quality indicators within Western healthcare delivery. From the clientcentred perspective, good care is generally perceived to be a more individualized matter; good care is shaped in individualized situations between client and caregiver. Variety thereby seems to reclaim a central position in the definition of quality. In deciding upon and realizing this variable good care several authors stress the importance of reflexivity. Jeanette Pols argues that reflexivity, which she calls contextual reflexivity, helps to articulate what good care is by telling stories and sharing values among different involved parties. Examples of good practices and failures are both important to search for alternative ways of care delivery. This, she argues, could be "an interesting way to help professionals and patients striving for something as complex as good care" [13]. Rick Iedema et al. [8] also stress the importance of reflexivity in changing healthcare systems to learn from medical errors and go beyond blame. Furthermore, Tineke Abma [1] emphasises on the relevance of a dialogical reflexivity to solve issues influenced by taboo. Reflexivity, as Abma argues, is needed "to explore more deeply what seems to be essential to the participants themselves" [1]. According to these authors, reflexivity is to be seen as a way to deal with the divergent and complex health care delivery for which there is no singular notion of what good quality is. These studies show how reflexivity is a way to deal with the situated enactment of something as complex as quality of care, but they tend not to specify what reflexivity is precisely about.

In order not to take reflexivity as a solution, we explore reflexivity in practice by analysing how it is framed and which issues are articulated and excluded in attempts to improve quality in the care for older people. In doing so, we focus on quality improvement devices. To help define what 'good care' is, devices are rather consequential. Healthcare sees a proliferation of tools to support healthcare workers in their daily tasks, such as guidelines and protocols, IT based learning tools, and health records. These devices help to create order in socio-technical collectives such as healthcare organizations [5] and when improvements of these collectives are 
deemed needed, devices are powerful means to support change. This wide attention to quality improvement devices in healthcare coincides with the vast tendency of standardization in healthcare that resulted from the variation studies by Wennberg and Gittelsohn [19]. Based on these studies, which showed substantial treatment variation among care organizations in New England, they claimed that variation was mainly a consequence of irrational behaviour of care professionals and that variation was a problem in terms of quality. This was one of the key initiatives to enact variation as a problem and lead to a call for changes in the education of medical professionals and the production of quality improvement devices like guidelines and protocols [18].

As an interesting contrast, in prevailing discussions on quality in care for older people, quality improvement devices are not to contribute to reducing variation, but to a situated reflection and better variation. Where the calls for innovation in care for older people and the proliferation of the development of evermore standardized organizational devices may thus at first sight thus seem contradictory, Michel Callon argues how these devices can be seen to be part of a "dual process of 'complexification' and 'simplification'" [7]. Both processes, which are mutually dependent, are fundamental for organizations to adapt to internal and external changes and to allow for creativity and innovation and improvement of the services.

Characteristics of the work of caring for older people make a focus on devices extra valuable. This care sector has similarities to organizations in the broader health and human services sector with regards to the kinds of 'goods' these organizations deliver, since what these organizations do is provide:

service [which] is the result of long-standing cooperation between several actors involved in its design and realization and [where] customers pay not for a specific material good but for the organization of a complex system of action that enables them both to progressively become aware of what they want and to express and fulfil this wish [7].

Instead of delivering a tangible and visible 'product', health and human service organizations deliver intangible things like care and services. As noted certain variability is needed for good care to be delivered. But variety poses an interesting and complex problem with regard to the stability of these services. By being intangible, the coordination of the quality in health- and human services sectors is not easily guaranteed. Quality improvement devices translate 'actions into words' by articulating what a service is. Once clearly framed these visible services can not only be managed, but also be observed and guaranteed when needed. Callon speaks of these devices as 'writing and rewriting devices'. He argues how devices are being developed through 'successive adjustments', whereby the often implicit and invisible actions in work practices are gradually becoming visible by inscribing these actions into the devices. This demands for constant adjustments. In this process of making health services visible some sorts of variety is to be allowed for to deliver good care. This means that reflexivity needs somehow to be embedded in devices that seek to improve healthcare delivery. This framing of reflexivity in quality improvement devices provides an interesting field of studying what reflexivity actually does and how specific forms of care work are enacted in devices. 
Interesting from the approach of Callon are the two additional functions of writing and rewriting devices. The work of gradually discussing, articulating and defining the content of the work into the device simultaneously also impacts the work practices it is intended to serve. The devices are thus created while in use. So instead of 'implementing' instruments 'into' care practices, instruments are embedded in the organizational change process, thereby trying to prevent 'implementation problems' that often occur when development and implementation are mainly being treated as two separate worlds [20].

In this article we will analyse the writing and rewriting process of a quality improvement device, which aimed to transform organizations in care of older people to put the wishes of clients centre stage in the care delivery. The dialogues between caregivers and clients are seen as the central element to determine what 'good client-centred care' is at an individual level, and the shape of these dialogues was to be formalized in a device, called the Care Living Plan (CLP). This device aims at articulating and structuring reflexivity, and we therefore explore how reflexivity is being framed into the CLP, thereby addressing the relation between reflexivity, standardization and good care. Our aim is to contribute to the discussion on reflexivity by giving a more detailed account of what reflexivity does in determining good care and how devices can play a central role in this process.

In order to do so, we first explore the different notions of reflexivity in relation to development of devices. Then we focus on the CLP to show how there are different reflexivities at stake and closely examine which processes and persons should be reflexive to improve client-centred care. We then turn towards how the shaping of reflexivity in the CLP leads to tensions between uniformity and allowing for local differences. Finally we show how in daily care practice care staff balances between different kinds of options in deciding what good care is. In the conclusion, we analyse the consequences of our analysis for the study of the relationship between reflexivity and quality improvement devices.

\section{The Multiple Meanings of Reflexivity}

Reflexivity is a multi-faceted concept meaning various different things and used in various and sometimes opposing ways. Reflexivity is used to refer to characteristics of humans, as distinguishing feature of certain professional groups, as methodological virtue in the social sciences, as belonging to machines that automatically respond to signals (i.e. reflexes) of the outside world, as constitutive aspect of modern societies [4] and much more. Given these widely diverse and contrasting understandings, it is important to clarify the notion of reflexivity and to understand what the role of reflexivity in quality improvement devices might actually be.

Reflexivity is one the one extreme used to refer to fully automated responses to signals, like in machines or in the human brain reacting to a stimulus. On the other extreme, it is attributed as something that makes you see things comprehensively, or as a special element of certain groups, such as experts, professionals or academics [9]. These two extremes differ in the need for conscious action to be involved. The former is in general more rigid and formalized, whereas the latter form of reflexivity 
is associated with more conscious thinking, pondering and deliberately choosing. Often the more mechanical reflexivity is seen as a characteristic of machines, and the more conscious reflexivity is mainly perceived as a characteristic of humans [9]. Michael Lynch has provided an open ended, though quite extensive, list of the various meanings of reflexivity based on which he concluded that a common denominator for all the 'reflexivities' is that they "involve some sort of recursive turning back, but what it does turning, how it turns, and with what implications differs from category to category" [9].

Lynch criticizes the 'special status' that is so often assigned to reflexivity as an academic virtue, to which academics have special access. He argues that instead reflexivity should be seen as:

an unavoidable feature of the way actions (including actions performed, and expressions written, by academic researchers) are performed, made sense of and incorporated into social settings. In this sense of the word, it is impossible to be unreflexive [9].

Consequently, reflexivity is an element of all practices and not an extra competence or ability of certain groups. Yet, when it is impossible to be unreflexive, it begs the question why there are such high hopes of enhancing reflexivity through the development of organizational devices as it would assumingly be inherent in social action and therefore already 'be there'. However, what reflexivity does, when and how and by whom it should be supported or diminished in order to reach the intended aims of improving the quality of care is a question that remains unaddressed in Lynch' analysis. For the purpose of the actors in our study, reflexivity still needs to be made specific in its purposes for improving healthcare practices.

In the writing and rewriting devices, Callon shows how the relevant service aspects are progressively discussed among some of the workers and inscribed in the device. This gradual act of "putting the service provision into words" (ibid, p. 194) resulted in these service organizations in manuals for employees prescribing how to do their job. These manuals were regarded as only drafts and required constant revision to match the changing environment. Interestingly, although reflexivity was central in the process of writing and rewriting, since it demanded constant turning back, reflexivity was reduced to a minimum in the use of the manuals by the employees. The employees were not supposed to give much own interpretation of what good quality of service was in the service delivery. Variety is in this case thereby not reinforced for those working primarily in the service delivery. Callon thereby analyses a specific way of framing reflexivity which is, perhaps unsurprisingly, not the only one.

Lucy Suchman [15] shows how reflexivity is not an aspect of formalized methods but rather an inherent aspect of everyday activities of workers. In her study on the work of office workers, that archive documents in a law firm, Suchman shows that these office workers have seemingly simple, standard and unreflexive archiving jobs. This work is regarded by others in the organization as 'routine work' which they oppose to 'knowledge work' which is typically performed by those at higher positions in the organization. Suchman challenges this idea by showing how the 
archiving job, in fact requires a great deal of insight and judgments regarding the case and as such cannot be carried out routinely. The notion that knowledge work is the reflexive thought work and routine work is work that is characterized by practically 'doing stuff' therefore proves problematic. Routine and knowledge work are not dichotomous and are not characteristics of certain professional groups, but instead are distributed over different workers. Her analysis reveals how there are many ideas associated with professional labour that are based on problematic assumptions about the nature of reflexivity. Seemingly simple tasks like archiving often comprise both routine and knowledge work and work that is regarded as routine should not automatically be seen as non-reflexive. This case reveals how there often are stereotypes and simplified views of what work entails [14] and that finding out what reflexivity is and does requires a situated way of observing. By pointing out these complex interactions between so called 'knowledge' and 'routine' work, Suchman tries to show how there are unacknowledged reflexive workers that need to be articulated as reflexive, and knowledgeable, in order to understand their work.

Both Suchman and Callon show us how reflexivity can be 'positioned' both in workers and in devices itself, without being defined in one case as a cognitive process and in the other as a 'reflex'. The general notion that devices posses an automated reflexivity and humans are generally associated with a more conscious form of reflexivity is too general and demands for a closer and more in-depth analysis. By following the development and introduction of the Care Living Plan, we therefore shift the focus to how reflexivity is shaped into this device, which issues it articulates, and with what consequences.

\section{Practicing Reflexivity in the Care Living Plan}

In 2005 the Dutch Ministry of Health initiated a large quality improvement program for the Dutch care sector, called Care for Better. The aim of this program is to realize quality improvements mainly at the work floor levels of long term care organizations as mental health care, the care for disabled clients and care for older people (see for more extended descriptions of the Care for Better program: [16, 21]. One year after the program started with a series of improvement trajectories, Care for Better was extended with the development trajectories that aim to develop quality improvement devices to support organizations that provide care to older people to adhere to the Norms for Responsible Care. These norms have been agreed on by national stakeholders in the sector (which include professional organizations, the Healthcare Inspectorate and the Ministry of Health) to describe the quality standards that all organizations caring for older people are to meet. In these quality norms, 'good care' is determined on basis of increasing the quality of life of individual clients. Central in the Norms for Responsible Care is the division of quality of care delivery into four domains that each addressed another aspect of the total well-being of the client, respectively physical well-being (e.g. eating and drinking), living situation (e.g. privacy, feeling at home), participation (e.g. hobbies, social life) and mental well-being (e.g. mood changes). In care for older people 
there is traditionally the most attention for providing physical care and solving medical orientated problems, so the four domains broadened the way of looking at the older person. The Norms try to articulate increased attention for the background and life history of clients, to better understand who they are and where they come from. The developers thereby claim that the Norms for Responsible Care stimulate a holistic perspective that takes the whole person into account (Arcares et al., [3].

The development trajectories within this CLP was further developed, were to be aligned to the broader Care for Better program (i.e. the improvement trajectories), to overcome the implementation problems that often occur when development and implementation of improvement devices are isolated. The idea was that knowledge of the development of devices and the realities of changing care practice in the improvement trajectories could mutually benefit. In this way, knowledge could be shared and both developers and implementers of quality improvement devices could learn from each other. Making this connection can create devices that better match the complexities of care practice by actively trying to prevent implementation problems' [20]. Since the division between devices developed in one setting and implemented in the next was actively avoided, this part of Care for Better is an interesting empirical domain to study how reflexivity can be built into devices seeking to change practices.

One of the main issues in the Norms for Responsible Care was that organizations caring for older people should become more client-centred. The Care Living Plan (CLP) was introduced as a 'vehicle' to support this change [2]. The main aim of this device was to increase the attention for the voice of clients and to encourage care organizations to put the quality of life of the older person centre stage. The CLP tries to facilitate the dialogue between the client and caregiver and supports rearranging the care according to the wishes of the individual older person about how they wish to be supported in living their life. In order to do so, the CLP must guide the different professionals in the field to change the way they approach the client, ask them questions and arrange the care. The Professional Organization for Care Workers (named Sting) introduced the CLP as a device that accommodates the communication between caregivers and clients, by means of the CLP. It was developed in such a way to that it would reinforce reflexivity. Organizations providing care to older people were to develop their own version of the CLP, and by doing this they were forced to think about, formulate and take their situated organizational aspects into account. The Dutch government legally requires all organizations to have a CLP for all individual clients that receive care in nursing home facilities. Developing the CLP was thereby the start of the change process in which the CLP was to be nested into the 'new' (client-centred) way of working. As a consequence there was no actual 'implementation', in the sense that an instrument was developed in one context and implemented in the next, although many organizations and the project group themselves used the word implementation when referring to this embedded process. The strong conviction of Sting was that change is not realized when development and implementation are separated. Instead they steered for an organizational transformation towards client-centred care that was supported by and realized through the CLP. To stress this comprehensive change process, their motto for the board of directors of organizations providing care for 
older people was: "Implementation? Don't do it!". Their approach entailed that all sorts of organizational issues (e.g. the lack of staff, the management that did not facilitate) that stood in the way of the improvement were taken into account, since ignoring these would be problematic when making client-centred care 'work'.

To facilitate organizations in developing their own CLP, some prototype models were developed by different national healthcare improvement agencies. Sting was responsible for the development and coaching trajectory of the CLP, and in this process, they organized sessions between care organizations and selected five organizations that received individual coaching about how to change the organization into starting to become more client-centred by means of the CLP.

For our study we followed several of the interventions undertaken by Sting. We received four models of the CLP developed by four different care organizations that were derived from the more general national models. We analysed these and also compared them with the prototype models. The project leader of Sting was interviewed twice by both authors and there were also regular shorter telephone interviews with her about progress of the project. Notes of these telephone conversations were written out immediately after the conversation. One of us (EvL) observed the actions undertaken to facilitate the development and use of the CLP in three different nursing homes. Interviews were held with organizational project leaders and trainers (3 in total), nursing staff (2), involved quality managers (2) and meetings between organizational project teams were attended (6). Additionally EvL observed coaching sessions that were led by Sting, with health care professionals of different organizations (7).

The organizations we visited were typical for many care organizations of older people in the Netherlands. All were large, often merged organizations serving various sorts of care to the older population, like home care, day treatment, shortstay care like rehabilitation and observation and long-stay care for often severely ill older people. In total we conducted nine interviews and had thirteen days of participant observations. All interviews were transcribed verbatim and the notes of the participant observations have been worked up as soon as possible after the meetings. All fieldwork has taken place between January and July 2009.

\section{Different Practices and Different Reflexivities}

As stated above, Sting strongly emphasized how the change towards a client-centred organization affects all organizational processes and all workers within the organization. In this section we explore how care organizations of older people initiated change towards client-centred ways of care delivery We point out how there are different reflexivities within workers and the organizational processes, and realizing 'good care' in a client-centred way requires a very specific focus on which items are put centre stage and which are marginalized.

Although client-centred care as such was not new for most of the organizations, this way of looking at care called for substantial changes that affected all layers and processes in the organization; from the way daily care is delivered, to the ways in which the kitchen works, the reception is organized and the organizational policies 
are being effectuated. The project leader of Sting explained how also for example the staff in the centralized kitchen is assumed to change:

you cannot change the organization into being client-centred based on individual wishes of clients if for example the central kitchen says: Yes but lunch is only served at noon.

In this quote, she emphasized how achieving client-centred care was mot merely a change in the attitude of care workers involved in direct care for older people, but required changing all kinds of processes. If there are situations in which there is agreement that clients should be served the meals at different times, the facilities should find ways to accommodate this. ActiZ, the umbrella organization for care providers in long-term care, also stressed how the CLP is a multidisciplinary instrument with far reaching organizational implications. The care provided should be seen as an integral responsibility of all professionals involved, whereby the new way of working demands creativity and thinking in terms of what is possible instead of in terms of organizational routines [2]/14).

Though this sounded like a laudable aim for the device, it was still far from obvious to care workers that the CLP would actually serve them this, in their opinion, intrinsic part of their work. In a meeting with a change coach in one of the nursing homes seven nursing coordinators were asked to grade the degree of clientcenteredness of their ward. The marks given were between 7,5 and 8 on a scale from 1 to 10 (10 being the best, 1 the worst). However when also being asked to grade the degree of working with the CLP they graded it substantially lower: between 6 and 7 . This shows that, according to the nurses, the CLP is not needed for nursing staff to work in a client-centred way. When asked by the coach what should be changed in order to raise the mark for client-centred working by one point, the nurses mentioned aspects such as having more time, more resources and making sure that others in the organization also adjust to a more client-centred attitude Currently, this same nurse explained client-centeredness "stops at the elevator door", by which she meant that at the wards a client-centred attitude is more 'normal' than at other places in the organization. Despite the fact that the CLP is deliberately introduced as a multidisciplinary device that changes the organization and all its workers, it is by the nursing care staff still felt as if they are the only ones that work in client-centred ways yet. For other workers in the organization their new responsibilities seem to be more vague. Notably, client-centred working is not only perceived by nursing staff as something that is already done; when asked how to improve, nobody mentioned that learning to work with the CLP would improve in client-centred working.

On the CLP-forum (zorgleefplanwijzer.nl), the project leader of Sting responded to a question of an assistant-nurse about her work with the CLP:

I think it is the duty of all staff involved in working with clients to work in a client-centred way. For assistant-nurses it is good to know the clients' preferences about the care they receive, for example their preferred time for getting up. The trick is to offer the care in such a way that the client can be assured that it is provided in the way he wants it. You can tell the nurse who 
coordinates that the appointments you make with the client are being written down in the CLP.

The assistant-nurses should gear their activities towards the coordinator of the CLP, which is generally a nurse of the ward, but at the same time they are also assumed to have similar kinds of dialogues with clients as the coordinator nurse, since also their work should all be aimed at service delivery for the client. All involved workers were urged to be aware how they perform their work and check if this is (still) in accordance with the client to be able to change the care towards client-centeredness.

For some more indirect suppliers of care and service, like for example the laundry service, the centralized kitchen and the housekeeping facilities, the care process and client-centred care is situated at a bigger distance. Often these groups organize their work in more standardized way, such as by using a duty roster or divide the work in different tasks. The introduction of the CLP caused concern for a project leader in one of the organizations for these particular groups. She explained:

we have 26 different nationalities in our housekeeping staff. How do you think we should get them to have a dialogue with the client about how they want their room to be cleaned? Now they work via a duty roster that regulates that at 11 in the morning they come to make the beds.

Given the substantial linguistic and cultural differences among the staff, the project leader suggested that it is highly unlikely that all disciplines are able to have this conversation with clients. Beyond the practical limitations of not managing the language well enough, the actors within the organizations questioned whether it should be that all different disciplines should have discussions with clients how the particular care or service they provide is desired by clients and that they thereby should be reflexive in the same way. From the perspective of both the organization and the clients it may be unnecessary and perhaps also unwanted for all staff to have a discussion on their services with the clients. This example of the housekeeping staff brings forward the question of which aspects of care should be reflexive in what ways to realize the aim of client-centred care.

The assumption in the above quote, with granting workers new and different responsibilities, seems to be that all processes in the organization and the workers should change towards being reflexive in a conscious way through deliberately pondering and making choices. The work of some of the staff in nursing homes is, however, more prescribed than that of others. For example the housekeeping staff work via a duty roster and precisely defined tasks. By following strict instructions, the service delivery is constant and can be guaranteed. For the success of the CLP and the care in client-centred ways, it is necessary to determine if all of the staff should be reflexive in the same way. It might well be that some of the work can still be arranged via a duty roster, although the total service for clients, since the dialogue of how this room should be cleaned has been performed at another moment. Both ways of delivering care are fundamental to the quality of service. It is thereby thus not the question whether certain members of staff within the organization are capable of being reflexive, since, as Michael Lynch has noted, 
reflexivity is an inherent element of all practices. It is specifically the question who should be reflexive at what moment about which issue in order for the aims of the CLP to succeed.

Where the organization of care delivery in organizations for older people used to be more of a mix between routine and knowledge work, divided over different professional groups, the introduction of the CLP changes this balance. Reflexivity as conscious thinking is reinforced strongly, but which professional groups should be reflexive in this way to accomplish client-centred care was largely left undefined. Other reflexivities, such as automated forms of reflexivity, were not specifically articulated either. With the focus on a more pondering mode of reflexivity, the question who should be doing their work in more prescribed ways to realise clientcentred care was absent from the discussion in the trajectory. We believe, on basis of our empirical findings that in order to come to more productive devices for clientcentred care, there is a need to articulate more specifically which professional groups are to be reflexive about which issues in which ways.

\section{Writing and Rewriting the CLP}

There are, as we explored in the previous section, organizational processes that greatly differ in their degree of more or less standardized processes. In this section, we will explore in more depth the processes of how the CLP is being created and transformed in written form in order to bring about the change towards a clientcentred organization. We will show that the choices that the organizations made in the design of the CLP, created different consequences for reflexive use. The design was, as we will point out, generally leaving many aspects 'open', which required from its users different reflexive capacities.

When the CLP was introduced in the field of care for older people, several of the national healthcare improvement agencies published supportive material such as prototype models, instructions and implementation suggestions to help care organizations realize the change. ActiZ focussed explicitly on the fact that the CLP should not be a 'rigid' device. Instead it should be used as a device that guides the actors in certain directions without prescribing in detail what to do. As one of their supporting documents read:

The model is not accidentally flexibly designed. Users find their own ways to get familiar with the vision behind the model and the way of working. So the texts in the model are for supportive purposes and the forms are examples. [2]

And they go on explaining:

The Model CLP is explicitly not a fixed questionnaire that is to be filled out by certain staff members, who would thereby have a client-centred CLP. What it does is to give an as overview that is as complete as possible of all the subjects that could be relevant for a client to do the right things (given the circumstances). (ibid.) 
By emphasising the flexibility of the CLP model, the model is believed to be suited to the diversity in caring for older people. The choice that the texts are only mere suggestions instead of instructions, has the consequence that development of the organizational CLP is a reflexive activity. After all, the prototype is only one way of making a CLP and care organizations should reflect on what content is most suitable for their own organization.

When following different care organizations for older people in their ways of changing and developing the CLP, noticeably all organizations seemed to strive for a uniform CLP for their whole organization. As the organizations that were part of this study were often merged facilities, serving many different forms of care (e.g. day treatment, home care, 24-hrs. care) to older persons with various and diverse health needs, the different wards within the organization have quite specific characteristics: they vary in sorts of clients, work methods, tools to support their work and require different aspects to be observed, taken action upon and report on. Consequently these wards have created their ways of providing 'good care' also through their own forms, files, and supportive materials. It is this variety that reflects different sorts of good care. Interestingly, despite all these differences, organizations strived to create one uniform CLP for all care groups within their organization, whereby the CLP substituted some of these local ways of working. This choice for uniformity, supports internal work processes such as centralised administration and meets ICT requirements for the electronic patient record. Adherence to external norms like specific quality standards and quality control were also reasons to strive for a uniform CLP. The uniformity of the CLP however seemed to produce frictions by allowing for these local diversities and had implications for the positioning of reflexivity.

The strive for uniformity was not easily accepted by all. In one of the care organizations, the content of the CLP was discussed in a working group with representatives of all different nursing home locations within the organization. The group, mostly consisting of managers and central staff members, decided on the content of the CLP through discussion, debate, consensus, and collaboration. The organizational project leader emphasized that it was important that the working group searched for shared 'aspects'. These shared aspects were then included in the CLP. This caused confrontation in the working group. The project leader remarked:

They repeatedly say 'yes, but we are used to...' [referring to their own wards] and all of the time I had to correct them by saying there is no 'we'. You know, you have to forget the old to be able to tolerate something new.

The point that there was no longer a 'we' suggested that the space for those aspects not commonly shared by all representatives of the wards, in other words those aspects that were not uniform, were reduced in the CLP. Those aspects that did not fit into the general picture became somewhat problematic to include in the CLP. Allowing for reflexivity in the development of the CLP was bounded to a specific type of reflexivity, namely the reflexivity that was part of the uniform 'we' and not the specific and localized 'we' of the individual wards. All these differences between the locations were, in a way, blinded out by the uniform CLP. The requirement of only including the commonly shared 'we' led to tensions that, 
according to some representatives, followed from important differences not being inscribed in the CLP. The project leader explained:

you are faced with a lot of differences per unit. Some units have, for example, many clients with a multi-cultural background and things just go differently there. So we had to emphasize constantly, it's not about the individual; it's about the common denominator. What do we all have in common? That was a great barrier.

She explained that there are differences in how care is being provided, for example older persons with a multi-cultural background have other traditions and other ways of dealing with disease and illness than other clients, but still the CLP should capture only those elements that are of shared concern for all the different care groups. Likewise, the variety in health status of older people is also not specifically acknowledged in the uniform CLP. Older people, especially frail older persons, who are often admitted to these care facilities, are faced with a complex diversity of health needs. As a physician, specialized in the care for older people described to us: when you start to change something in the life of frail older people, the effects are often unforeseen. This complexity of their total medical and wellness needs makes it by definition an individualized assessment. Although the design of the CLP acknowledges this diversity in health needs, by not specifying too much, the other side of the coin is that by focusing solely on the commonalities, many specific elements are not included. This choice had consequences in terms of the use of the CLP and the reflexivity of the users.

One of the consequences of the uniformity of the CLP was that the care staff using the CLP had to decide for themselves which matters are relevant to address in the conversation with their clients. The uniformity results in openness in the CLP that, as the project leader explained was to be filled in by the users of the CLP:

They [the users] are guided in a particular direction in such a way that you can determine the things that they should take into consideration. But how deep they address these things is up to the caregiver. It gives them more responsibility, I think this is a good thing. We have given it [the CLP] so much flexibility that you can use it for all different client groups. So that is a lot. But this results, for example, in a Care Living Plan in which the subjects of orientation and disorientation are mentioned only briefly, [though these are] things that are very important on wards with many psycho-geriatric clients.

By guiding the users without prescribing, the CLP thus acknowledged that there are local differences and there is variation in how to deal with these differences, but this variation is to be 'added by' the caregivers and client in interactions with each other and the device. It thereby requires new capacities of the caregivers as they ought to capture the specific complexities of the situation in the device themselves, whereas the same counts for the clients. Although client-centeredness was not perceived to be new for nurses, to articulate specifically what wishes of clients were and how these should be written down in the device asked for different competencies, as was acknowledged by one of the project leaders in an organization: 
Most nurses know very well what is important; I must say I'm not so well informed about that [...] It is the professional behaviour that you are to expect from nurses. Most nurses are used to this personal balancing and judging of things. They have been doing this before. For example at the wards for psycho-geriatric clients we had observation-lists, these were lists that they had to fill out and they could choose between three options: client can do it independently, with some help or with a lot of help. But these were very predetermined. This [pointing at the CLP] demands that people have to keep asking questions, it is much more focused on the conversation instead of the observation.

An important difference between the high mark for client-centred care professionals gave their own wards and the notion of client-centred care that was being built into the CLP, was that now client-centred care could not be achieved without the inclusion of clients themselves in a conversation. The clients thereby have to (learn to) articulate their wishes, and the nurses have to find ways to unravel these wishes, which is particularly challenging as this assumes a cognitively coherent self that is not always to be found on psycho-geriatric wards. This is an intended but at times problematic addition to depending mainly on the observational skills of nurses alone. The model of ActiZ, the umbrella organization of care institutions, emphasized how specific 'accents' were captured in the CLP through the clients who are to express their wishes:

The model does not differentiate in different care groups: it does not distinguish in diagnose groups or somatic or psycho-geriatric care. For all quality of live is strived for. What is important is to observe, listen and collaborate - with clients, their families and amongst each other (all that are involved). Based on the model organizations can make their own specific models suiting different care groups. The model is applicable for the whole care spectrum from low to high complex care work and from care at home to intramural care. Accents will evolve by itself guided by the perspective of the client.

It is interesting how ActiZ and the care organization argue how the accents and the local aspects that are of importance will emerge in and off themselves, simply by using the CLP. By developing the CLP in these ways, reflexivity is not only embedded in the device, it is also at the same time allowing for the device to be used in reflexive ways. This approach is likely to reinforce the variation that is necessary to realize good care, but provides little articulation of good quality that is hampered by reflecting on the issues that may not be in the interest of clients - but that for example stem from pressured staff agenda's. There is an assumption that any variability that emerges in the reflexive dialogue between care worker and client is also desired.

The CLP often served as a means to reform the paper record of the care organization into a uniform system. All the current different files and forms that can be there for good reasons, for example by supporting care staff in their observations, were in a way ignored to make place for one new and uniform CLP. Interestingly, it seemed that local complexities of the different locations were often being silenced 
instead of being challenged in the device. Tensions between local diversity and the idea of organizational uniformity were often solved by either leaving the specific local aspects out of the model completely as far as these were not shared among all, or it was solved by naming all the possibilities in the model. To include the 'couleur locale', the specific individualized and localized aspects, in the new way of working, demanded reflexive action from the users of the CLP. Unsurprisingly, the uniformity of the CLP sometimes led to the use of alternative devices on the work floor, which had a effect that was contrary to the intentions to reduce the variation in files and forms and which certainly was not the kind of reflexivity that was appreciated by those promoting the CLP. A team leader explained that she worked at a short-stay ward where clients could stay for a maximum of 12 weeks to recover from a hospital stay; on wards such as these, some items of the CLP (e.g. an extensive description of the clients life history) were not necessary to know. So this team leader took the initiative to reform the CLP together with colleagues from the same kind of ward. This initiative was critiqued by the organization that urged to keep the device uniform and its development centralized.

The choice for a uniform device as such was not a discussion item in the project meetings, although the decision what should be the content was. All actors agreed that the model helped to realize client-centred work, but there seemed to be different matters at stake in this decision to stick to uniformity. It facilitated comparability between wards, which was deemed relevant for external accountability of the organization; uniformity was also seen as an important prerequisite for integration with the organizations' information system and for the transition to the electronic client record. Although the caregivers requested that the CLP supported their work routines, the management and staff were troubled with the fact that the model had to fit in other developments and requirements of the organization, and therefore needed to be standardized. The frictions seem to stem from the fact that the model serves many purposes and makes clear that the reflexivity pursued here can no longer be seen as contributing to client-centred care alone. Instead, when there is less space for local specification of the issues that are key in various wards, this means that specific ways in which reflexivity used to be reinforced are now reduced. As the CLP is not merely a tool for realizing client-centeredness at an individual level, but also an accountability tool, a communication tool, and a part of the health record and as these different purposes are hard to reconcile, the CLP risks the possibility that incompatible forms of reflexivity are combined.

\section{The Dialogue as Central Aspect in Determining 'Good Care'}

Perhaps surprisingly for those not familiar with the field of care for older people, getting to know the wishes of clients and taking these wishes as a starting point for the organization of care is a rather new aspect for both the client and the caregivers. During our research we regularly heard of cases where, for example, an older person came to a nursing home and had since been drinking white coffee. This was served to her without anyone asking how she actually wanted her coffee, and the client assumed that it was for health reasons that the caregivers served milk. As we saw 
earlier, client-centeredness as such is not felt to be new by care workers, but explicitly asking clients what they feel is important and writing this down in a formalized tool is not a common practice. A nurse admitted, to his shame, that in the past the nursing staff sometimes heard about the crucial aspects of the life of a client at their funeral. Before, in all those moments of care delivery, many relevant sides of the client often remained rather absent. The CLP was perceived as a device that forced these workers to have a dialogue with clients and find out who they are, what their interests are, what background they have and a broad range of other things, thereby allowing the caregivers to gain better insight into whom their clients are. Consequently, the articulation of these appointments in the CLP is making these dialogues visible. This interaction between caregiver and client can be conceptualized as a writing and rewriting process. The four domains that are central in the vision behind the CLP, namely physical well-being, living situation, participation and mental well-being forced the dialogue to be beyond medical aspects alone.

In a meeting, a coordinating nurse explained that choosing is difficult for clients, as well as for caregivers. Many clients have to make decisions and articulate wishes on issues on which they have rarely had to choose in these healthcare contexts, such as how the care is to be provided. Therefore, caregivers not merely have to start listening to the wishes of the clients, but rather have to experiment in how to get clients to know their wishes, and also assess how such wishes relate to other notions of 'good care'.

Both client and care worker are adjusted to how the system of care works, thereby needing to explore the new opportunities and boundaries of client-centred care. The boundaries of the wishes of the clients were a point of concern for most of the caregivers. In the Netherlands, the care for older people is a sector with rather scarce resources. Often there is a shortage in personnel and financial budgets are tight. The concern was how to deal with questions from older people when it was difficult to organize this, knowing the rather limited resources. Caregivers have to balance the wishes of the client to what is possible and desirable knowing the personal situation of the client, but also with keeping the broader context in sight. A nurse interviewed described this work quite well. She explained that she coordinates the care for a client who prefers to stay in bed the whole day. She knows however that this client benefits from having a fixed daily rhythm in which she also spends some hours during the day in a chair. The severe wounds on the legs of the client will worsen when she spends the whole day in bed. From the nurses' perspective of good care, the client ought therefore to be out of bed some time during the day. The nurse explained how she negotiated with the client about this situation:

I try to explain it to her. Like: 'do you remember when you were lying all day in the bed? You had wounds on your heel and toes and you said these hurt a lot. When I leave you in bed, I know these wounds are getting worse.' I deliberately plan this conversation with her when she is sitting in the chair, so I can talk with her how she feels at that time. She then always says that she is feeling much better and she can go out when her children come to visit. So I try to reinforce the positive of being out of bed, to hopefully increase her consciousness of this. It is repeating the message over and over again. 
The nurse explained that she negotiated each agreement as she wrote it down in the CLP:

We came to an agreement on the necessity of the daily rhythm. All agreements that follow from this we have discussed, like: All right I want you to leave the bed in the morning, at what time suits you best? She explained to not want to leave the bed before breakfast, which was all right with me. [...] So we make compromises and agree on the care as it will be provided. She has to be reminded of these agreements sometimes, but I consider it part of my professionalism to remind her of that and insist that we keep to it.

By specifically articulating what the appointment is that should be written down the CLP serves as a writing device. The device mediates in the negotiations between the caregiver and the client and demands for efforts of both to articulate what good care should look like in this particular situation. This relational aspect is an important aspect of delivering good care and demands a close negotiation and trust between caregiver and client in order to succeed. This relation aspect is formalized in the dialogue and interactions between client and care worker that is thereby facilitated by the CLP. The added value of the CLP, as expressed by this nurse, was that these appointments were written down. The act of inscribing these agreements in the CLP gave the appointments a different status: it aligned the nurse and the client towards what was agreed and it also coordinated them over time [6], but it also served as a justification towards others (i.e. other professional groups in the organization, relatives of the client, management).

In this dialogue, the cooperation does require thoroughly pondering of both the caregiver and the client. If the nurse blindly follows the expressed wish of the client, this client would be lying in her bed all day long since that is the wish she wants to see fulfilled by the nursing staff. However, the nurses' view on the situation is different and this requires a dialogue in which both decide which action is meeting the needs.

This example illustrates the negotiations between caregiver and client. Negotiations as these are not always easily achieved. As the above examples illustrate, the care workers are likely to find ways to balance between wishes of clients, organizational opportunities and good care, but the care for older people knows a vast population of frail clients with for example reduced cognitive capacities which can seriously hinder the dialogue. To arrange client-centred care for older people with psychogeriatric problems other efforts have been observed. For example, caregivers asked the close relatives of clients with severe dementia for the information on the life history and of habits and other specificities. Whereas these practical solutions are of course possible, it points to some complexities of reflexivity. Since the reflexive dialogue is central in the practice of unravelling the clients' wishes and find clues to what good care for this client is, those clients that lack capacities to have this conversation are in trouble. The reflexivity required from clients is thus bounded by their cognitive state, but perhaps also by other situations that hinder this dialogue (e.g. older people with impaired autonomy).

What the above example again shows is that, once related to the product of good care, reflexivity is no longer an answer or an aspect that needs to be strengthened 
through organizational devices such as the CLP; such devices become a topic for analytical scrutinizing how reflexivity gets framed and which issues are put centre stage or marginalized in the reflection that is enacted. To further tease out the theoretical implications of this case, we now return to the debate on reflexivity in the improvement of work practices.

\section{Conclusion}

In this article we analysed the complex trajectory of the introduction of an organizational device that explicitly aims to allow for reflexivity in order to improve its quality, while at the same time formalizing this reflexivity in a device. For the realization of good care, especially in terms of client-centeredness, reflexivity is often posed as one of the answers. We hope to have shown how the debate about reflexivity however needs to be shifted from the reflexivity as an answer, towards constructing a more specific picture, in which the inclusion and exclusion of certain aspects of work in organizational devices both enhances and reduces reflexivity in different ways.

To analyse the CLP in terms of the intense successive writing and rewriting practices [7], in which developers aim to create a device that is applicable to all work processes, only partly suffices. The intentions of those developing the CLP were to enhance certain kinds of variety in work processes, instead of diminishing variety by describing work tasks in detail, like Callon analyses. By seeking for those universal elements in care delivery (e.g. the 'common denominator', as one of the interviewees termed the attempts to come to uniformity), the CLP actually created space for substantial variations in good care. After all, diversity in health status, needs and wishes are diverse and the CLP is a device that allows for this 'good variation', i.e. the variation that is needed to deliver good care. The openness of the CLP can also create problems in terms of variation and reflexivity. By making the CLP such a uniform and multiply applicable device, some kinds of wanted variation becomes absent or invisible. We pointed out how elements of orientation and disorientation were only mentioned shortly in the CLP while many relevant nuances are left out. The CLP rests strongly on the idea that all these nuances are coming back in through the dialogue between client and caregiver. It is not unlikely that some of these issues might not be addressed in the dialogue and are not inscribed in the CLP, whereby problematic variation easily occurs. Especially in those situations where the older people's health status reduces the possibilities for a dialogue on wishes the chances that 'good variety' is missed will likely decrease.

The ways of constantly refining the device, by including different actors in the development and in rewriting the device when new insights so required, was a fruitful way to create a device that better meets the realities of work practices. One way of including these actors in the CLP was assuming a democratization agenda of reflexivity, in which all actors should be reflexive in the same way, namely the conscious pondering way. We conclude that this proved problematic in providing good, client-centred care. Reflexivity is, as we described, generally positioned in humans, methods or things, whereby reflexivity as attributed to humans is often 
a priori associated with careful scrutinizing, weighing of options and conscious choice making, and reflexivity of things is seen as the machine-like 'if-then' response of reflex-ivity. We have shown how this distinction between these reflexivities is inadequate, as it separates cognitive and mechanized reflection as two different mechanisms rather than leaving space for enacting reflexivity as interplay of reflexes and considerations in human-device interactions. Reflexivity thereby gets disconnected from the issues in quality of care assurance and improvement, as the example of the housekeeping staff showed us. As the device was to be related to practices of 'good care' that were formalized in the Norms for Responsible Care, thereby enacting a specific notion of client-centeredness, the developers of the device did not aim at facilitating all kind of reflexive practices of users. Choices needed to be made, thereby having consequences for which reflexivities could be included and which not. Despite the importance to connect reflexivity to quality issues in care delivery, the main attention of the improvement agents was on strengthening reflexivity as a cognitive and conscious process. The CLP tried to accomplish that caregivers rethink their actions instead of responding in automated reflex-ive ways towards situations, thereby implying that client-centred care consisted of consciously reflected thinking and acting. Our analysis pointed out that a 'democratization of reflexivity' in which all actors are assumed to be reflexive in the same way may not be helpful. Developing the CLP asks for a specific definition of who should execute what kind of reflexivity about which issues to realize good client-centred care.

Not specifying who should be reflecting on what and when reflexes were preferred over rethinking practice was consequential in that it allowed the developers of the CLP to leave the actors unspecified or regarding them all as expressing the same form of reflexivity. Lucy Suchman pointed out the differences between routine and knowledge work. As our case also underlines, routine and knowledge work are not characteristics of different professional groups. However, though we acknowledge that all workers capable of being reflexive, routinizing work, that means enacting it as work that does not need directly reflection on clientcentred care seems necessary, just like enacting other work as deliberate pondering reflexivity and knowledge work. Now the users of the CLP were 'configured as everybody' [12]. Where Oudshoorn et al. pointed out that such a user-configuration is particularly problematic as it results in the exclusion of certain relevant groups in discourses of instrument development, we conclude that including too many of the same reflexive groups in the discourse is equally problematic. Arguably the exclusion of actors leads to problems in terms of allowing for diversity, but as the case of the CLP shows, the inclusion of all users as having the same reflexivity, insufficiently reduces diversity and fails to specify where more automated 'if-then' routines are a more productive form of reflexivity for ensuring the quality of care for older people. In the case of the cleaning of the rooms that would probably need to be changed at the level of-centrally-adjusting the duty rosters of the cleaners to daily schedules of clients. The analysis of reflexivity thereby points out that explicitly excluding some users from the practices of instrument development seems a necessity when creating instruments that formalize reflexivity productively. 
Acknowledgments We are grateful to all the respondents and Sting for their time and insights in their work and thoughts. Furthermore, we thank Roland Bal, Bethany Walters-Hipple, the reviewers for the helpful comments to improve this paper and Sarah-Sue Slaghuis for doing one of the interviews. This research has been funded by ZonMw, The Netherlands Organisation for Health Research and Development (grant number: 53430001).

Open Access This article is distributed under the terms of the Creative Commons Attribution Noncommercial License which permits any noncommercial use, distribution, and reproduction in any medium, provided the original author(s) and source are credited.

\section{References}

1. Abma, T. A. (2001). Reflexive dialogues: A story about the development of injury prevention in two performing-arts schools. Evaluation, 7(2), 238-252.

2. ActiZ. (2006). Verantwoorde zorg: visie en verwezenlijking. Werken met het model Zorgleefplan.

3. Arcares, AVVV, LOC, NVVA, \& Sting. (2005). Op weg naar normen voor Verantwoorde zorg.

4. Beck, U. (1997). The reinvention of politics: Rethinking modernity in the global social order. Cambridge: Cambridge Polity Press.

5. Berg, M. (1998). The politics of technology. On bringing social theory into technological design. Science, Technology and Human Values, 23, 456-490.

6. Berg, M. (1999). Accumulating and coordinating: Occasions for information technologies in medical work. Computer Supported Cooperative Work, 8, 373-401.

7. Callon, M. (2002). Writing and (re)writing devices as tools for managing complexities. In J. Law \& A. Mol (Eds.), Complexities: Social studies of knowledge practices (pp. 191-217). Durham, London: Duke University Press.

8. Iedema, R. A. M., Jorm, C., Long, D., Braithwaite, J., Travaglia, J., \& Westbrook, M. (2006). Turning the medical gaze in upon itself: Root cause analysis and the investigation of clinical error. Social Science and Medicine, 62, 1605-1615.

9. Lynch, M. (2000). Against reflexivity as an academic virtue and source of privileged knowledge. Theory Culture and Society, 17(3), 26-54.

10. Mol, A. (2006). Proving or improving: On health care research as a form of self-reflection. Qualitative Health Research, 16(3), 405-414.

11. Mol, A. (2008). The logic of care. Health and the problem of patient choice. London, NY: Routledge.

12. Oudshoorn, N., Rommes, E., \& Stienstra, A. (2004). Configuring the user as everybody: Gender and design cultures in information and communication technologies. Science, Technology, \& Human Values, 29(1), 30-63.

13. Pols, J. (2006). Accounting and washing: Good care in long-term psychiatry. Science, Technology, \& Human Values, 31(4), 409-430.

14. Suchman, L. (1995). Making work visible. Communications of the ACM, 38(9), 56-64.

15. Suchman, L. (2000). Making a case: 'Knowledge' and 'routine' work in document production. In P. Luff, J. Hindmarsh, \& C. Heath (Eds.), Workplace studies: Recovering work practice and information system design (pp. 29-45). Cambridge: Cambridge University Press.

16. Strating, M., Nieboer, A., Zuiderent-Jerak, T., \& Bal, R. (2008). Evaluating the care for better collaborative: Results of the first year of evaluation. Rotterdam: Institute of Health Policy and Management.

17. The, A. (2008). In death's waiting room: Living and dying with dementia in a multicultural society. Amsterdam: Amsterdam University Press.

18. Wennberg, J. E. (1984). Dealing with medical practice variations: A proposal for action. Health Affairs, 3(2), 6-32.

19. Wennberg, J. E., \& Gittelsohn, A. (1973). Small area variations in health care delivery. Science, 183, 1102 .

20. Zuiderent-Jerak, T. (2007). Preventing implementation: Exploring interventions with standardization in health care. Science as Culture, 16, 311-329.

21. Zuiderent-Jerak, T., Strating, M., Nieboer, A., \& Bal, R. (2009). Sociological refigurations of patient safety. Ontologies of improvement and 'acting with' quality improvement collaboratives. Social Science and Medicine, 69(12), 1713-1721. 